\title{
So Far So Good
}

A year has passed since I have taken over as Editorin-Chief of Respiration. During this period major changes have taken place. As far as the Editorial Board is concerned, the addition of associate editors and the introduction of correspondence by fax for the initial handling of all manuscripts have proved to be very successful innovations. Dr. N. Cherniack, Newark, N.J., Dr. F. Kummer, Vienna, Dr. R. Loddenkemper, Berlin, for clinical investigations, and Dr. D. Paterson, Oxford, for basic science investigations have done a sterling job in getting expert reviews from members of the Editorial Board as well as from outside reviewers they chose for specific topics. A special thank you to all of them! The main success lies in the faster handling of the review process from receipt of a manuscript to the first verdict, which was lowered by more than half from 15.8 to 7.6 weeks. We intend to become even faster as publication speed is essential in an area such as medicine where the half-life of scientific knowledge is short. In 1999 we welcome three more associate editors, Dr. P.M. Gustafsson, Skövde, Dr. D. Olivieri, Parma, and Dr. C. Page, London.

The feedback on the introduction of the various new sections of Respiration has been very positive; we therefore continue all of them in 1999. The six thematic reviews on tuberculosis have indeed been a state-of-theart series; the individual articles were written by leading specialists in the field. 1999 will be devoted to another very timely topic: the lung in the immunocompromised. Other very popular sections are the Eye Catcher and What
Is Your Diagnosis? Traditionally the case reports were proportionally overrepresented in Respiration; their number will therefore be somewhat reduced in the future by applying stricter acceptance criteria. So far there is a shortage in the sections: Basic Science Investigations, Clinico-Pathological Conferences, Technical Notes, Rapid Communications and Letters to the Editor. Contributions are welcome!

On the other hand, the overall number of submitted manuscripts is increasing rapidly, which surely is good news! The overall rejection rate during the years 19951998 has been around $50 \%$, but will have to become higher in order to further increase the scientific quality of Respiration. Thus, in 1999 the number of pages in each of the six issues will increase only slightly, but thanks to the commitment of the publishing house, S. Karger AG, the price for individual subscriptions will remain unchanged at CHF 98.-. This is truly competitive in comparison to other major journals in the field of respiratory medicine and was confirmed by a rapid increase of personal subscriptions during 1998.

So far so good, as I suggested in the title of this note! But I consider this first year as just a start in the right direction. This direction is a journal of excellent scientific value, a good mix of the various sections, fast manuscript handling time, and with an appeal to a global readership. High aims, let's go for them!

C.T. Bolliger

\begin{tabular}{ll}
\hline KARGER & ( ) 1999 S. Karger AG, Basel \\
Fax +4161306 1234 & \\
$\begin{array}{l}\text { E-Mail karger@karger.ch } \\
\text { www.karger.com }\end{array}$ & Accessible online at: \\
http://BioMedNet.com/karger
\end{tabular}

